\title{
Pierre Bec, Florilège en mineur. Jongleurs et troubadours mal connus
}

\section{Giuseppe Noto}

\section{(2) OpenEdition \\ 1 Journals}

\section{Edizione digitale}

URL: http://journals.openedition.org/studifrancesi/32791

DOI: 10.4000/studifrancesi.32791

ISSN: 2421-5856

Editore

Rosenberg \& Sellier

\section{Edizione cartacea}

Data di pubblicazione: 1 décembre 2005

Paginazione: 612-613

ISSN: 0039-2944

\section{Notizia bibliografica digitale}

Giuseppe Noto, «Pierre Bec, Florilège en mineur. Jongleurs et troubadours mal connus», Studi Francesi [Online], 147 (XLX | III) | 2005, online dal 30 novembre 2015, consultato il 19 avril 2021. URL: http:// journals.openedition.org/studifrancesi/32791 ; DOI: https://doi.org/10.4000/studifrancesi.32791

Questo documento è stato generato automaticamente il 19 avril 2021.

\section{(c) (i) (9)}

Studi Francesi è distribuita con Licenza Creative Commons Attribuzione - Non commerciale - Non opere derivate 4.0 Internazionale. 


\title{
Pierre Bec, Florilège en mineur. Jongleurs et troubadours mal connus
}

\author{
Giuseppe Noto
}

\section{NOTIZIA}

PIERRE BEC, Florilège en mineur. Jongleurs et troubadours mal connus, Orléans, Paradigme

(«Medievalia», 49), 2004, pp. 405

1 L'attenzione nei confronti dei poeti 'minori' è una sorta di fiume carsico che, sin dalla ottocentesca fondazione della provenzalistica come disciplina scientifica (penso soprattutto all'edizione dei derniers trobadours di Paul Meyer), affiora di tanto in tanto negli studi dedicati alla poesia trobadorica, ovviamente con prospettive critiche differenti a seconda dei differenti periodi.

2 In tempi recenti le ricerche di questo tipo hanno trovato particolare vigore, soprattutto per merito del compianto Antoine Tavera (per il quale «réhabiliter la recherche de l'originalité» anche nei trovatori 'minori' era, come confessa lui stesso, "une espèce d'idée fixe»: De Bergerac à Narbonne: trop de troubadours négligés, in Toulouse à la croisée des cultures. Actes du $\mathrm{V}^{\mathrm{e}}$ Congrès International de l'Association Internationale d'Études Occitanes, Toulouse 19-24 août 1996, Pau 1998, pp. 133-151, a p. 149, nota 1), di alcuni studiosi legati alla rivista statunitense «Tenso» (si vedano le riflessioni di Mark Taylor e di Kathryn Klingebiel rispettivamente nei numeri 12.2 (Spring 1997), pp. 81-88, e 13.1 (Fall 1997), pp. 1-23) e di Saverio Guida (Trovatori minori, Modena 2002).

3 Come già Guida, anche Bec nel suo Florilège parte dal presupposto che l'etichetta di 'trovatore minore' non trova necessario riscontro nella condizione originaria ed anzi spesso può dipendere da accidenti meccanici o scelte soggettive all'interno del processo di diffusione e trasmissione, oppure ancora da pregiudizi critico-estetici di tipo modernizzante.

4 Diverso è invece il pubblico cui i due studiosi destinano le loro opere, e conseguentemente diverso è il modo in cui esse sono costruite: se il libro di Guida, 
tanto per le dense riflessioni teoriche sul concetto di 'minore' nella storiografia letteraria (in particolare in quella dedicata alla poesia medievale in lingua d'oc) quanto per il rigoroso lavoro di tipo ecdotico ed esegetico su testi trobadorici prima trascurati dalla critica, è chiaramente rivolto ad un pubblico di specialisti, il volume curato da Bec è pensato in principal modo «aussi bien pour le médiéviste non philologue que pour le lecteur occitanophone d'aujourd'hui» (p. 15).

Così si spiega la scelta dello studioso francese di non procedere ad una nuova edizione critica delle poesie antologizzate, ma di rifarsi, se necessario 'ritoccandole', ad edizioni preesistenti (ma a volte la scelta cade, a mio avviso poco opportunamente pur in un contesto sostanzialmente divulgativo, su edizioni filologicamente 'superate' da altre più recenti e scientificamente più fondate, come nel caso dei componimenti di Raimon Jordan e di Grimoart Gausmar inseriti nel florilège, per i quali si ignorano le edizioni rispettivamente di Stefano Asperti e di Anna Ferrari). Così si spiegano - ancora - la «normalisation graphique» che viene condotta sui testi (e che comprende la notazione dell'apertura delle vocali e, se necessario, dell'accento tonico, secondo un uso non di rado presente nella provenzalistica francese e quasi del tutto ignoto invece a quella italiana), la totale assenza di apparato critico e l'essenzialità di quello esegetico (ogni poesia essendo dotata di un breve 'cappello' introduttivo e di note estremamente stringate), essenzialità che non significa tuttavia sottrarsi all'atto interpretativo per eccellenza, ovvero la traduzione (a fronte), magistralmente approntata da Bec e presentata tendenzialmente verso per verso.

6 L'antologia raggruppa in sei partizioni ("Le registre du grand chant courtois"; "Le registre pieux"; "Le registre popularisant"; "L'anti-courtoisie"; "La didactique courtoise"; "Lo gai saber") sessanta poesie che coprono un arco cronologico di quasi quattro secoli (l'ultima essendo datata 1471) e che trovano il loro denominatore comune nel fatto che per lo più si tratta del prodotto di poeti (in totale 58) «dont on n'a conservé que quelques rares textes» (p. 13); nella scelta trovano adeguata rappresentazione i componimenti del periodo tardo, ormai distante cronologicamente e culturalmente dai trovatori della 'classicità' (in particolare unica del canzoniere che $\mathrm{i}$ provenzalisti siglano $f$, quello dei derniers trobadours di Meyer) ed anche la produzione così «académique et bridée» (p. 11) - legata ai concorsi annuali banditi dal Consistori del Gay Saber (fondato a Tolosa nel 1323) tesi a promuovere l'attività in versi in lingua d'oc $\mathrm{e}$ che dànno luogo ad una poesia, spesso di carattere morale o religioso, che oggi appare di un certo interesse solo quando è ispirata da avvenimenti locali o contemporanei. 